\title{
Functional diagnostics in the training process of young biathletes
}

\author{
Nina Komarova*, Lyudmila Maydokina, Vera Tsybusova, Olga Mikaeva,'Vera Starostina \\ National Research Mordvinian State University named after N.P. Ogarev, 430005, Saransk, Russia
}

\begin{abstract}
Using modern technical means, which give information about the functional state of an athlete's organism, can significantly increase the effectiveness of the training process control. Among such devices specialized hardware-software complex "Omega-C" is often used. The aim of the pedagogical experiment was the effectiveness substantiation of using functional diagnostics opportunities during the training process of young biathletes. 15-16 year-old biathletes were divided into two identical according to physical readiness groups. The control group trained according to typical biathlon training program with earlier planned loads. In the experimental group the volume and intensity of the training loads were selected individually and were oriented toward functional state indices of an athlete's organism at the moment, which precedes the beginning of the work. Modern technology "Omega-C" introduction in the experimental work helped a coach and a sports doctor to monitor the quality and level of adaptive processes of 15-16 year-old athletes. It provided balance between high physical loads and health preservation. Physical state deviations registration among biathletes helped to correct timely the training process.
\end{abstract}

\section{Introduction}

Modern training process of biathletes is characterized by intensive regimen of competitive activity and constant increase of the training loads. Athletes themselves are very often at the edge of their physical and psychological abilities. In this connection it is especially urgent to control physical readiness and functional state of athletes. It is necessary to realize timely operative control over sports fitness, adaptive reactions of an organism and its reserve capacities estimation in the training and competitive activity of young biathletes $[1,2,3,4,5]$.

In biathlon an athlete's organism adapts to the training loads during a long time period and the attempts to intensify this process very often lead to injuries, overtraining state and deadaptation. In case of inadequate physical loads selected by a coach compensatory reaction of an organism doesn't happen. That is why taking into account and analysis of organism adaptation dynamics is very important in training process control, when a coach has the aim to prevent over-tension and adaptation violation in young athletes $[6,7,8,9]$.

* Corresponding author: ninasm@bk.ru 
Nowadays the method of functional diagnostics is very popular. It helps to follow the level of physical and psychological state of an athlete, helps to reveal adaptive abilities of an athlete's organism and the dynamics of their development. Functional diagnostics results analysis and summarizing would help to realize a purposeful selection of working capacity rehabilitation means among young biathletes and vary the training loads depending on current state $[10,11,12]$.

The aim of the research work is effectiveness substantiation of functional diagnostics means use in the training process of young biathletes.

\section{Materials and Methods}

We organized a research work on the basis of the State Autonomous Establishment of the Republic of Mordovia "Sports school of the Olympic reserve of winter kinds of sport". 20 young biathletes at the age of 15-16 took part in the research. They were divided into two identical according to physical readiness groups. The control group trained according to typical biathlon training program with earlier planned loads. In the experimental group the volume and intensity of the training loads were selected individually and were oriented toward functional state indices of an athlete's organism at the moment, which precedes the beginning of the work.

\section{Results and Discussion}

Physical state of young athletes' organism diagnostics was held during a yearly training cycle 2018-2019 with the help of the hardware-based complex «Omega-C». It helped to control current physical state of an athlete at any time and place. Portability and compact size of this diagnostic system helped to realize the control over the currant functional state of an athlete at any time and any place regardless of the chosen regimen of training lessons (everyday, independent or at a training camp).During the whole period of the research biathletes from the experimental group fulfilled known to them procedures of study at the hardware-based complex before the beginning of the training lesson. High level of «Omega-C» sensitivity concerning different inner and outer influences gave an opportunity to estimate objectively general and physical state of an athlete's organism, his sports fitness and everyday changes in 15-16 year-old biathletes' organisms, connected with the training cycle, the day of the week, with personal life events didn't stay without attention.

«Omega-C» complex realizes diagnostics on the basis of neurodynamic analysis of heart rate variability. It helps to realize an objective estimation of an organism state. After the diagnostics with the help of this complex a coach and a sports doctor get information concerning the level of an organism adaptation to loads (\%), the training level of the heart $(\%)$, index of sports fitness $(\%)$, index of organism energetic provision (\%).

General conclusion concerning the level of an athlete physical state is shown in a form of gradations : perfect physical state, sports form index -5 points ; good physical state, sports fitness index -4 points ; satisfactory physical state, sports fitness index -3 points ; unsatisfactory physical state, sports fitness index -2 points; poor physical state, sports fitness index -1 point.

When physical state was 5 points the loads were recommended without restrictions, 4 points - developing trainings, without « stress » loads, 3 points - only supporting trainings, 2 points- only rehabilitation loads, pharmacological correction, 1 point- additional study, rest, pharmacological correction.

Using current state diagnostics a coach can predict the influence of physical loads and prevent tiredness and stress. That is why it is important to follow the state of an athlete's 
organism before, during and after the trainings.

On the basis of the received results in the experimental group of 15-16 year-old biathletes urgent and perspective correction of the training process loads was held.

In $80 \%$ of cases we realized urgent negative training load correction. Taking into account unsatisfactory state of an organism the load was decreased by a coach for $30-50 \%$. If the state continued to be unsatisfactory it was possible to decrease the load also for 30$50 \%$. At the same time, it was recommended not to reject physical loads at all. In terms of organism systems tension it was obligatory to take into account previous states. If a coach saw that the state of a young athlete became worse the load increased additionally.

Using «Omega-C» system a coach could correct the load precisely in accordance with the abilities of an organism, selecting its optimal volume.

On the basis of the received results we selected the volume of the load both in general and for each kind of the training lesson, including warming-up and physical training. It means that a coach had an opportunity to optimize athletes' indices during the training lessons and competitions using the results of noninvasive analysis. It helped to increase readiness and decrease tiredness of athletes and control the effectiveness of the chosen principles and programs of trainings individually and for each athlete.

The effectiveness of functional diagnostics in controlling the training process of young biathletes is proved by the indices increase, which reflects the level of physical readiness among young biathletes.

At the beginning of the experiment biathletes' physical readiness indices in both groups were identical. At the end we defined different degree of its results improvement. The results of physical readiness improvement in the control group of biathletes were insignificant. In the experimental group most indices improvement was statistically valid $(\mathrm{P}<0,05)$ (table 1).

Table 1. Special readiness indices among young biathletes

\begin{tabular}{|c|c|c|c|c|c|}
\hline \multirow[t]{2}{*}{ № } & \multirow[t]{2}{*}{ Control exercises } & \multicolumn{2}{|c|}{ Control group } & \multicolumn{2}{|c|}{ Experimental group } \\
\hline & & $\mathrm{BE}$ & $\mathrm{EE}$ & $\mathrm{BE}$ & $\mathrm{EE}$ \\
\hline 1 & $\begin{array}{l}100 \mathrm{~m} \\
\text { seconds }\end{array}$ (from the start) & $16,92 \pm 0,08$ & $16,71 \pm 0,09$ & $17,02 \pm 0,08$ & $16,25 \pm 0,08$ \\
\hline 2 & $\begin{array}{l}100 \quad \mathrm{~m} \text { with synchronous } \\
\text { single step motion, seconds }\end{array}$ & $17,01 \pm 0,1$ & $16,73 \pm 0,8$ & $17,00 \pm 0,2$ & $16,13 \pm 0,19 *$ \\
\hline 3 & $\begin{array}{llr}100 \quad \mathrm{~m} & \text { with } & \text { synchronous } \\
\text { double } & \text { poling } & \text { motion } \\
\text { seconds } & & \\
\end{array}$ & $16,8 \pm 0,09$ & $16,32 \pm 0,07$ & $16,79 \pm 0,1$ & $15,04 \pm 0,09$ \\
\hline 4 & $500 \mathrm{~m}$ (from the start), min. & $1,30 \pm 0,2$ & $1,25 \pm 0,21$ & $1,29 \pm 0,3$ & $1,15 \pm 0,2$ \\
\hline 5 & $3000 \mathrm{~m}, \mathrm{~min}$. & $10,40 \pm 2,8$ & $10,21 \pm 2,7$ & $10,37 \pm 3,4$ & $9,56 \pm 3,2$ \\
\hline 6 & $5000 \mathrm{~m}$, min. & $17,50 \pm 5,2$ & $17,08 \pm 5,3$ & $17,48 \pm 4,9$ & $16,5 \pm 5,0$ \\
\hline 7 & $\begin{array}{l}\text { With the speed } 60 \% \text { from } \\
\text { maximal one, } \mathrm{m}\end{array}$ & $15878 \pm 17,5$ & $16284 \pm 17,4$ & $15877 \pm 17,9$ & $16973 \pm 17,7 *$ \\
\hline 8 & $\begin{array}{l}7,5 \mathrm{~km} \text { with two firing lines, } \\
\text { min. }\end{array}$ & $34,28 \pm 4,5$ & $34,05 \pm 4,6$ & $34,23 \pm 0,25$ & $33,45 \pm 0,4^{*}$ \\
\hline 9 & $\begin{array}{l}10 \mathrm{~km} \text { with two firing lines, } \\
\text { min. }\end{array}$ & $44,23 \pm 4,9$ & $43,56 \pm 4,9$ & $44,30 \pm 4,7$ & $43,05 \pm 4,8$ \\
\hline
\end{tabular}

Notes: $B E$ - beginning of the experiment, $E E$ - end of the experiment, * - validity $P \leq 0,05$.

Skiing $100 \mathrm{~m}$ with synchronous double poling motion in the experimental group of biathletes improves for 1,75 seconds $-10,4 \%(\mathrm{P} \leq 0,05$.), in the control group for 0,48 seconds $-2,9 \%$. Thus, the results increase in the experimental group was higher for 1,27 seconds $-7,5 \%$, than in the control group $(\mathrm{P} \leq 0,05$. $)$. 
Time of skiing $100 \mathrm{~m}$ with synchronous single step motion in the experimental and control groups improves for 0,89 seconds $-5,2 \%$ and 0,28 seconds $-1,6 \%$. The result improvement in skiing $100 \mathrm{~m}$ with synchronous single step motion in the experimental group is higher, than in the control group for 0,61 seconds $-3,6 \%$.

The results of skiing $5000 \mathrm{~m}$ among biathletes from the control group improve for 0,42 min $-2,4 \%$. The result of skiing $5000 \mathrm{~m}$ among biathletes from the experimental group improves for $0,98 \mathrm{~min}-5,6 \%$. Time improvement of skiing $5000 \mathrm{~m}$ in the experimental; group is higher, than in the control group for $0,56 \mathrm{~min}$ or $3,2 \%$.

Time of skiing $100 \mathrm{~m}$ from the start among biathletes from the control group increases for 0,29 seconds $-1,6 \%$, in the experimental group for 0,66 seconds $-3,8 \%$. Time of skiing improvement in the experimental group is higher for 0,38 seconds $-2,2 \%$, than in the control group.

The result of skiing $500 \mathrm{~m}$ from the start in the control group increases for $0,05 \mathrm{~min}(3,8$ $\%)$. The same index in the experimental group - for $0,14 \min (10,9 \%)(\mathrm{P} \leq 0,05)$. In the experimental group the increase was higher, than in the control group for $0,09 \min (7,1 \%)$ $(\mathrm{P} \leq 0,05$.).

The result of skiing with the speed $60 \%$ from maximal one in the control group increases for $406 \mathrm{~m}(2,5 \%)$. In the experimental group this index increases for $1096 \mathrm{~m}(6,5$ $\%)$. The increase of this index is higher in the experimental group for $690 \mathrm{~m}-4 \%$.

Time of skiing $7,5 \mathrm{~km}$ with two firing lines in the control and the experimental groups increases for $0,23 \mathrm{~min}-0,7 \%$ and $0,78 \mathrm{~min}-2,3 \%$. Time of skiing 7,5 $\mathrm{km}$ with two firing lines in the experimental group is higher, than in the control group for $0,55 \mathrm{~min}-1,6 \%$.

Time of skiing $10 \mathrm{~km}$ with two firing lines in the control group increases for 0,67 $\min$ or $1,5 \%$, in the experimental group for $1,25 \min$ or $2,8 \%$.

Thus, time of skiing this index increase is higher in the experimental group for $0,58 \min$ or $1,3 \%$.

\section{Conclusions}

The results of the held research prove the effectiveness of functional diagnostics use for the training process optimization among young biathletes. Modern diagnostic equipment use gives an opportunity to develop the indices of young biathletes during the training lessons and competitions using the results of noninvasive analysis; decrease the risk of getting an injury; increase readiness and decrease athletes' tiredness; control the effectiveness of the chosen principles and training programs individually for each athlete. It in general significantly influenced the effectiveness of the training process.

\section{References}

1. V.P. Vlasova, L.E. Ignatieva, N.A. Komarova, A.R. Mamaev Theory and Practice of Physical Culture, 6, 31 (2019)

2. L.E. Ignateva, E.E. Elaeva, Yu.V. Kireeva, A.S. Kairova Culture physical and health, 5(60), 1924 (2016)

3. A.S. Kairova, N.A. Komarova Urgent problems of physical culture and sport at a modern stage, 34-38 (2018)

4. K.K. Markov, V.L. Sivokhov, O.A. Ivanova, D.A. Semenov Fundamental research works, 12-1, 179-182 ( 2014)

5. V.S. Budagaev, V.Yu. Lebedinskiy Irkutsk State Technical University bulletin, 1, 362-365 (2011)

6. A.A. Antonov, N.E. Burov Intensive therapy bulletin, 3, 8-12 (2010)

7. E.V. Gubanov Training loads correction of young athletes on the basis of current control over functional state (2001) 
8. V.A. Kurashvili Sports innovations bulletin, 3, 8-10 (2011)

9. N.P. Grachev Training loads organization in a yearly cycle of training 15-16 year-old racing skiers taking into consideration the factors, which limit working capacity (2002)

10. A.S. Bakhareva, V.I. Zalyapin, E.V. Kharitonova., G.V. Budanov, Human. Sport. Medicine, 18(3), 30-36 (2018)

11. S.G. Sorokin Omsk scientific bulletin, 5(132), 171-174 (2014)

12. A.S. Kuznetsov, Z.M. Kuznetsova, Russian Journal of Physical Education and Sport, 14(4), 5-7 (2019). DOI: $10.14526 / 2070-4798-2019-14-4-5-7$ 